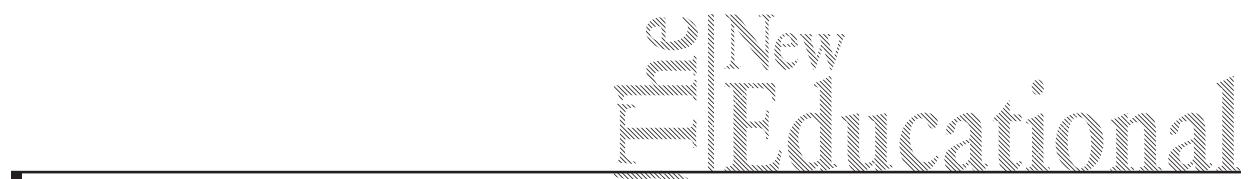

Marta Licardo, Majda Schmidt

Slovenia

\title{
Why is Self-Determination Important for Students with and without Disabilities in Vocational Education?
}

DOI: 10.15804/tner.2016.46.4.17

\begin{abstract}
The purpose of the study was to determine differences in self-determination between high school students with and without disabilities and to determine the influence of three predictors of self-determination in vocational education: gender, group and grade point average. Research was done by comparing students with the method of pairs. The results show that students with disabilities have a lower level of self-determination than their peers; significant predictors of self-determination are group and grade point average. Results reveal important fields of intervention for self-determination development, especially for students with disabilities in vocational education. This is also the first study of student self-determination in Slovenian vocational education with specific cultural and education background.
\end{abstract}

Keywords: self-determination, vocational education, students with disabilities, academic achievement.

\section{Introduction}

Self-determination skills are important because they enable students to cope with challenges in the educational environment. In various models, self-determination includes facets such as: self-regulation, autonomy, empowerment, self-advocacy, self-awareness, problem solving, etc. (Soresi et al., 2011; Wehmeyer 
et al., 2000; Wehmeyer, 1999; Deci and Ryan, 1985, 2008; Chirkov et al., 2003). Application of the self-determination construct occurs in disability and psychology-related issues, examined in developmental theories, interventions, follow-up studies, assessment instruments, curricular materials, and instructional models especially in western countries (Algozzine et al. 2001; Chambers et al. 2007). In psychology, the theory of self-determination is based on basic psychological needs (autonomy, competence and social relatedness), which motivates individuals to develop their potential (Deci and Ryan, 1985; 2000; 2008; Ryan and Niemec, 2009; Niemec et al., 2006; Ryan et al. 2006), while in the disability field, self-determination is more often presented as a concept of skills or within areas of disability support, services and advocacy (Field and Hoffman, 1994; Martin and Marshal, 2004; Wehmeyer, 1996). The process of becoming self-determined may be described as a process where we learn problem solving, choice making, goal setting, autonomous behavior, empowerment, self-regulation, and self-realization (Wehmeyer et al., 2000). More studies indicate (Wehmeyer, 1996; Wehmeyer and Garner, 2003) that self-determination in students with disabilities has a significant impact on postsecondary outcomes, such as living arrangements, current and past employment situations, postsecondary education status, and community integration outcomes.

\section{Research Problem}

The self-determination model by Field and Hoffman (1994), which we used in our research, focuses on the variables of self-determination that are important to achieve self-regulation, autonomy and independence, (e.g., know yourself, value yourself, plan, act and learn from experience). We use this model because it is a mixture of both the mentioned approaches and measures variables that are within an individual's control; results show motivational factors and skills of students. The focus of our study is on students with disabilities and comparison with their peers without disabilities, as we believe understanding of both groups can promote efficient support in the mentioned skills for both groups of students.

\section{Research Focus}

Our study is the first research in Slovenia into self-determination in general and also the first research done with the use of the method of pairs into population of 
students with and without disabilities in vocational education, by which we wished to confirm the results of self-determination research in the international context and to acquire more accurate knowledge of self-determination in order to suggest possible interventions of support for students.

\section{$\underline{\text { Research Methodology }}$}

\section{Research General Background}

The purpose of the study was to determine differences in self-determination between high school students with and without disabilities in vocational schools and to determine the influence of three predictors, gender, grade point average and group.

\section{Research Sample}

The research sample consisted of high school students $(n=122)$ from eight different vocational schools and was based on the method of pairs. Students in both groups were equalized in pairs by age, gender, school program, and GPA. The first group consisted of students with disabilities $(n=61)$, the second group consisted of students without disabilities $(n=61)$; by gender, the sample was composed of 72 males and 50 females. Most students were aged $16(n=79)$ and $17(n=36)$ and a few students were 18 years old $(n=7)$.

All the students with disabilities were in a regular classroom. They had the formal status of students with special educational needs and received additional professional support. The group of students with disabilities consisted mostly of students with (specific) learning disabilities (45 students) and with mild cognitive disabilities (10 students). Four students had emotional and behavioural disabilities, one had mild visual impairment and one had autism.

\section{Instrument and Procedures}

The instrument used was the Self-Determination Student Scale (Hoffman et al., 2004), which measures cognitive, affective, and behavioural factors related to self-determination developed by Field and Hoffman (1994). The Self-Determination Student Scale (SDSS) is a validated, 92-item, self-report instrument that measures emotional and cognitive aspects of student self-determination.

The SDSS is delineated by five components of the model (a) know yourself, (b) value yourself, (c) plan, (d) act, and (e) experience outcomes and learn. Each component score and self-determination total score is done on the basis of correct 
and false criteria for answers. A total self-determination score is the sum of the five subscales: Know Yourself, Value Yourself, Plan, Act, and Experience Outcomes and Learn. Analyses in our research were made for the total score of self-determination and for the subscales separately.

Validity of the scale was measured by a principal component analysis. The percentage of the explained variance of the first component is $74.75 \%$. The diagram of eigenvalue showed one main component, i.e., self-determination. Reliability of SDSS was measured by Cronbach's alpha, which was 0.91 for Self-determination in the original version (Hoffman et al., 2004, p. 26); in our research, Cronbach's alpha was 0.90 for Self-determination. Cronbach's alpha for the subscales in the original version is 0.93 for Know Yourself, 0.46 for Value Yourself, 0.90 for Plan, 0.63 for Act and 0.93 for Experience Outcomes and Learn (Hoffman et al., 2004, p. 26).

\section{Data Analysis}

To analyse structural differences in self-determination between students with and without disabilities we used a discriminant analysis and to analyse the influence of gender, group and grade point average we used a multiple regression analysis.

\section{Research Results}

\section{Structural Differences in Self-determination Between Students with and Without Disabilities}

To determine structural differences in self-determination between the students with and without disabilities we used a discriminant analysis.

Table 1. Results of discriminant analysis

\begin{tabular}{lcccccc}
\hline Function & Eigenvalue & $\begin{array}{c}\text { Percent of } \\
\text { variance }\end{array}$ & $\begin{array}{c}\text { Canonical } \\
\text { correlation } \\
\text { coefficient }\end{array}$ & $\begin{array}{c}\text { Wilks } \\
\text { Lambda }\end{array}$ & Chi square & Sig. \\
\hline 1 & $\lambda$ & $\%$ var & Cc & $\Lambda$ & & P \\
\cline { 2 - 7 } & 1.675 & 100 & 0.791 & 0.374 & 115.604 & 0.000 \\
\hline
\end{tabular}

The results indicated that the students with disabilities showed less self-determination than the students without disabilities. We found one significant discriminant function $(\Lambda=0.374 ; p=0.000)$, with eigenvalue $\lambda=1.675$. The correlation coefficient with linear function is $\mathrm{C} c=0.791$. 
Table 2. The structure of discriminant functions

\begin{tabular}{lcc}
\hline $\begin{array}{c}\text { Self-determination } \\
\text { components }\end{array}$ & $\begin{array}{c}\text { Standardized discriminant } \\
\text { function coefficients }\end{array}$ & Correlation coefficients \\
\cline { 2 - 3 } & $\boldsymbol{\beta}$ & $\mathbf{r}$ \\
\hline Act & 0.74 & 0.932 \\
\hline Experience Outcomes and Learn & 0.283 & 0.644 \\
\hline Value Yourself & 0.235 & 0.675 \\
\hline Know Yourself & 0.002 & 0.595 \\
\hline Plan & -0.057 & 0.545 \\
\hline
\end{tabular}

The standardized discriminant function coefficients indicated the contribution of each predictor, showing differences between the students with and without disabilities are mostly expressed in the Act $(\beta=0.74)$ component, less in the components Learning from Experience $(\beta=0.283)$ and Value Yourself $(\beta=$ $0.235)$, and even less in Know Yourself $(\beta=0.002)$ and Plan $(\beta=-0.057)$, which is a rather surprising result, at least for the Plan component. The correlation coefficients for self-determination components are between 0.932 (for Act) and 0.545 (for Plan).

\section{Gender, Group and Grade Point Average as Predictors of Self-Determination}

A multiple regression analysis was conducted to examine the relationship between self-determination and potential predictors; gender, group (students with and without special needs) and GPA. Additionally, we analysed each of the components of self-determination to examine the relationship between the above components and predictors.

The assumptions of multicollinearity, normality residuals, independence errors and homoscedasticity were confirmed. The multiple regression model with three predictors produced adjusted $R^{2}=.295 ; F=17.78 ; p<0.000$. Independent variables gender, group and GPA explain $30 \%$ of the variability of self-determination. Statistically significant predictors for self-determination are group $(p<0.000)$ and grade point average ( $p=0.02)$. Group is the most frequent predictor of self-determination components. 
Table 3. Results of multiple regression analysis for self-determination and components Know Yourself, Value Yourself, Plan, Act, and Experience Outcomes and Learn

\begin{tabular}{|c|c|c|c|}
\hline Variable & B & SEB & $\beta$ \\
\hline \multicolumn{4}{|l|}{ Self-determination } \\
\hline gender & 0.081 & 1.979 & 0.003 \\
\hline group & -12.653 & 1.947 & $-0.501^{\star *}$ \\
\hline GPA & 3.165 & 1.337 & $0.185^{\star}$ \\
\hline \multicolumn{4}{|l|}{ Know Yourself } \\
\hline gender & 0.091 & 0.413 & 0.016 \\
\hline group & -3.354 & 0.406 & $-0.609^{\star *}$ \\
\hline GPA & 0.033 & 0.279 & 0.009 \\
\hline \multicolumn{4}{|l|}{ Value Yourself } \\
\hline gender & -0.605 & 0.343 & -0.122 \\
\hline group & -3.206 & 0.338 & $-0.656^{\star *}$ \\
\hline GPA & 0.035 & 0.232 & 0.01 \\
\hline \multicolumn{4}{|l|}{ Plan } \\
\hline gender & -0.13 & 0.516 & -0.019 \\
\hline group & -3.818 & 0.508 & $-0.571^{\star *}$ \\
\hline GPA & 0.163 & 0.348 & 0.036 \\
\hline \multicolumn{4}{|l|}{ Act } \\
\hline gender & -0.282 & 0.514 & -0.032 \\
\hline group & -6.508 & 0.505 & $-0.762^{\star \star}$ \\
\hline GPA & 0.307 & 0.347 & 0.053 \\
\hline \multicolumn{4}{|c|}{ Experience Outcomes and Learn } \\
\hline gender & -0.128 & 0.396 & -0.023 \\
\hline group & -3.473 & 0.389 & $-0.637^{\star *}$ \\
\hline GPA & 0.087 & 0.267 & 0.023 \\
\hline
\end{tabular}

In the self-determination components, independent variables explain $36 \%$ of the variability of Know Yourself (adj. $R^{2}=.356 ; F=23.33 ; p<0.000$ ), $43 \%$ of the variability of Value Yourself (adj. $R^{2}=.433 ; F=31.82 ; p<0.000$ ), and $32 \%$ of the variability of Plan (adj. $\left.R^{2}=.317 ; F=19.71 ; p<0.000\right)$. The greatest is $59 \%$ of the variability of the Act component (adj. $\left.R^{2}=.585 ; F=57.95 ; p<0.000\right)$ and $40 \%$ of the variability of Experience Outcomes and Learn (adj. $R^{2}=.396 ; F=27.44 ; p<$ 
0.000). In each of the four components of self-determination as a dependent variable statistically significant for the prediction is the Group independent variable $(p<0.000)$, while gender and GPA are not so important. In the self-determination components, unstandardized coefficient $B$ is equal to -6.508 in the Act component, which shows the largest decrease in Act in the students with disabilities in comparison to the other components.

\section{Discussion}

With the use of a structural analysis we analysed which components of self-determination indicate deficits in the students with disabilities compared to their peers. The results of the discriminant function showed strong differences between the students with and without disabilities in the Act component, moderate differences in the Learning from Experience and Value Yourself components and almost no differences in Know Yourself and Plan. The students with disabilities showed similar scores in self-knowledge, self-valuation, and planning, but differences occurred in the behavioural components, where self-determination should be enforced. The lowest component of self-determination in the group of students with disabilities was Act, which is related to executive functions. Further examination of variables for the Act component indicated that the students' functioning in the academic and social environments makes the difference. Variables consisted of the students' self-reported assessment in (a) ability to find support from other sources, e.g., in statements like "I do not know how to get support when I need it," "I do not know where to get help to decide what I should do after I finish school," and "If my friends criticize something I'm wearing, I do not wear it again", (b) ability to persist in activities, e.g." "When I want good grades, I work until I get them," "I give in when I have differences with others," "I'm easily discouraged when I fail," and "If I'm unable to solve a puzzle quickly, I get frustrated and stop", and (c) ability to overcome emotional obstacles (emotional self-regulation), e.g., "Criticism makes me angry," "I'm too shy to tell others what I want," "I'm too scared to take risks," and "I imagine myself failing before I do things" (Hoffman et al., 2004, p. 31).

Our results showed that self-determination does make a difference between the students with and without disabilities. The students with disabilities are challenged when they show self-determined behaviour. Namely, most of the students with learning disabilities have problems in social functioning for various reasons. Some of the common reasons are intra-individual, e.g., neurological and cognitive dys- 
functions that contribute to deficits in social skills, low self-esteem, comorbidity of learning disabilities with other problems like depression, anxiety, and other disabilities. Some of the reasons are environmental issues like exclusion from peers, obstacles connected with learning failure, disadvantages in local opportunities and little support in family because of family stress related to the child's disability (San Miguel et al., 1996).

Many researchers (Geary, 2006; Siegel and Ryan, 1989; Meltzer, 2007) have noted that the problems (especially in students with learning disabilities) correlate with slow cognitive development, weak motivation and self-regulation, low executive functions, and poor organizing skills, time management, learning cognition and metacognition, which might be the reason why the group is a stable predictor of self-determination. Problems in executive functions can be perceived through the students' below-average performance in learning, schoolwork, and persistence. These findings can be helpful in seeking more effective interventions for perceived weaknesses in self-determination.

The results of our multiple regression analysis show that self-determination directly relates statistically to academic achievement only on the general self-determination scale, but not in separate components. We assume the reasons for the lack of these data are the small sample of students, low number of students with disabilities with high GPA, and low variation coefficient in the self-determination score of the students with disabilities, which is coherent with most of the research that compares these two variables. For instance, Sarver (2000), who analysed correlations between self-determination and academic success, found that high levels of self-determination have a significantly positive correlation with GPA. Similarly, Martin et al. (2003) found that high levels of self-determination correlate with high grades in math, reading, and language in a smaller sample of students with disabilities. Research on students with learning disabilities and intellectual disabilities in inclusive education showed that students with high levels of self-determination achieve more learning and personal goals than their peers with low self-determination levels (Shogren et al., 2012). Some authors note the importance of the process through which students develop self-determination competences (Solberg et al., 2012).

Academic achievement is important for successful coping with challenges of students with disabilities, which we mentioned in the introduction. For students with disabilities it would, therefore, be necessary to gain self-determination skills, especially skills related to executive functions like planning and acting in the educational environment. 


\section{Conclusions}

We found specific differences in self-determination between the students with and without disabilities related to executive functions, with these the understanding of self-determination is more precise. Our results also indicate that being a student with special needs is the most evident predictor of self-determination; the other most important predictor is GPA, which shows important connections between these variables. Our study is also new regarding the cultural background, namely most of the studies on self-determination in education are from the USA (which is evident from the literature overview) and very few studies are from Eastern European countries, where education systems and cultural backgrounds are different. We can conclude that the self-determination construct is important for our students, too.

To achieve success, students should use cognitive, social, and emotional resources within themselves. Therefore, it is very important to support students to develop self-determination skills for better coping with the challenges they face. For more specific applications on the level of secondary education, we suggest implementing the self-determination model in schools as project work and systematic education of teachers and other education professionals, because they are not fully aware of how important self-determination is for students with disabilities. Schools should promote the ethos and school culture which allow for self-determination. Students with disabilities should be empowered to actively participate in their education, especially in procedures related to individualized education programs and transitions in education. Teachers could encourage students to speak up about themselves; also self-determination could be part of the methods of instruction, including goals for the development of self-determination, because self-determination skills are important in lifelong learning.

\section{References}

Algozzine, B., Browder, D., Karvonen, M., Test, D.W., \& Wood, W.M. (2001). Effects of interventions to promote self-determination for individuals with disabilities. Review of Educational Research, 71(2), 2019-277.

Chambers, C.R., Wehmeyer, M.L., Saito, Y., Lida, K.M., Lee, L., \& Singh, V. (2007). Self-determination: What do we know? Where do we go? Exceptionality, 15(1), 3-15.

Deci, E.L. \& Ryan, R.M. (1985). Intrinsic motivation and self-determination in human behavior. New York: Plenum.

Deci, E.L. \& Ryan, R.M. (2000). The 'what' and 'why' of goal pursuits: human needs and the self-determination of behavior. Psychological Inquiry, 11, 227-268. 
Deci, E.L. \& Ryan, R.M.. (2008). Self-determination theory: a macrotheory of human motivation, development and health. Canadian Psychology, 49, 182-185.

Chirkov, V., Ryan, R.M., Kim Y. and Kaplan, U. (2003). Differentiating autonomy from individualism and independence: a self-determination perspective on internalisation of cultural orientations, gender and wellbeing. Journal of personality and social psychology, $84,97-110$.

Field, S. \& Hoffman, A. (1994). Development of a model for self-determination. Career development for Exceptional Individuals, 17(2), 159-169.

Geary, D.C. (2006). Learning disabilities in arithmetic: Problem solving differences and cognitive deficits. In H.L. Swanson, K.R. Harris \& S. Graham (Eds.), Handbook of Learning Disabilities (pp. 199-212). New York: Guilford Press.

Hoffman, A., Field, S. \& Sawilowsky, S. (1996; 2004). Self-determination assessment battery user's guide. Detroit, MI: Wayne State University

Martin, J.E., Marshall, L.H., \& Sale, P. (2004). A 3-year study of middle, junior high and high school IEP meetings. Exceptional Children, 70, 285-297.

Martin, J.E., Mithaug, D.E., Cox, P., Peterson, L.Y., Van Dycke, J.L., \& Cash, M.E. (2003). Increasing self-determination: Teaching students to plan, work, evaluate, and adjust. Exceptional Children, 69, 435-447.

Meltzer, L. (2007). Executive function in education. From theory to practice. London: Guildford Press.

Niemiec, C.P., Lynch, M.F., Vansteenkiste, M., Bernstein, J., Deci, E.L., Ryan, R.M. (2006). The antecedents and consequences of autonomous self-regulation for college: a self-determination theory perspective on socialization. Journal of Adolescence, 29, 761-775.

Ryan, R.M., Deci, E.D., Grolnick, W.S. \& La Guardia, J.G. (2006). The significance of autonomy and autonomy support in psychological development and psychopathology. In D. Cicchetti \& D.J. Cohen (Eds.), Developmental Psychopathology: Theory and Method (pp. 795-849). New Jersey: John Wiley \& Sons, Inc.

Ryan, R.M. \& Niemiec, C.P. (2009). Self-determination theory in schools of education; can an empirically supported framework also be critical and liberating? Theory and Research in Education, 7; 263-272.

San Miguel, S.K., Forness, S.R., \& Kavale, K.A. (1996). Social skills deficits in learning disabilities: The psychiatric comorbidity hypothesis. Learning Disability Quarterly, 19(4), 252-261.

Sarver, M.D. (2000). A study of the relationship between personal and environmental factors bearing on self-determination and the academic success of university students with learning disabilities. Gainesville: University of Florida.

Shogren, K.A., Palmer, S.B., Wehmeyer, M.L., Williams-Diehm, K., \& Little, T.D. (2012). Effect of intervention with self-determined learning model of instruction on access and goal attainment. Remedial and Special Education, 33(5), 320-330.

Siegel, L.S. in Ryan, E.B. (1989). The development of working memory in normally achieving and subtypes of learning disabled children. Child Development, 60, 973-980.

Solberg, V.S., Howard, K., Gresham, S., \& Carter, E. (2012). Quality learning experiences, 
self-determination, and academic success: A path analytic study among youth with disabilities. Career Development and Transition for Exceptional Individuals, 35(2), 85-96.

Soresi, S.L., Nota, L. \& Wehmeyer, M.L. (2011). Community involvement in promoting inclusion, participation and self-determination. International Journal of Inclusive Education, 15 (1), 15-28.

Wehmeyer, M.L. (1996). Self-determination as an education outcome: Why is it important to children, youth and adults with disabilities? In D.J. Sands \& M.L. Wehmeyer (Eds.), Self-determination across the lifespan: Independence and choice for people with disabilities (pp. 1-14). Baltimore: Brookes.

Wehmeyer, M.L. (1999). A functional model of self-determination: describing development and implementing instruction. Focus on Autism and other Developmental Disabilities, 14, 53-61.

Wehmeyer, M.L., Agran M. \& Hughes C. (2000). A national survey of self-determination and student-directed learning. Journal of Special Education, 34 (2), 58-68.

Wehmeyer, M.L. \& Garner, N.W. (2003). The impact of personal characteristics of people with intellectual and developmental disability on self-determination and autonomous functioning. Journal of Applied Research in Intellectual Disabilities, 16, 255-265. 